\title{
Impact of Cognitive Predictors on Academic Performance among Undergraduate Learners
}

\section{Badgujar Vishal Bhagwan*, Helvinder Kaur, SantibuanaBinti Abd Rahman}

Royal College of Medicine Perak, Universiti Kuala Lumpur, No. 3 Jalan Greentown, 30450 Ipoh, Perak, Malaysia

Study Area: Perak, Malaysia

Coordinate: $4^{\circ} 45^{\prime} \mathrm{N} ; 101^{\circ} \mathrm{o}^{\prime} \mathrm{E}$

Key words: Academic competence, Test competence, Time management, Testanxiety, Strategies skills

\section{Introduction:}

Why do some students perform well academically while others do not? Generally, academic performance has been used to forecast accomplishment in school and so have certain strategic studies. Students' academic performance has been the subject of on-going debate among educators. In tertiary academic institutions, students' academic performance is based on grading system and remains as a common factor and baseline tool to evaluate progression of students' performance in every academic semester. Some factors could act as an activating event to students during their academic session in tertiary education in achieving and sustaining high grades in examinations. Some researchers impose questions on the validity and utility of academic performance scores or grades as a sole measurement of competency achievement (Allen, 2005). A

\section{Abstract}

The association of learning and study strategies on academic performance and students' academic years, across the two years enrollment of health science undergraduate learners $(n=130)$ is evaluated. A cross-sectional study design utilizing validated questionnaire was used to evaluate the test anxiety, academic competence, test competence, strategic studying and time management factors on academic performance. Data analysis was done in terms of descriptive and inferential statistics. Result revealed that strategic studying and academic performance was signif icantly associated when assessed across the two years of students' enrolment. Accordingly, the second-year students validated better study strategies skills $(3.57 \pm 0.2)$ as compared to the first-year students $(2.92 \pm 0.2)$, a statistically significant difference $(\mathrm{r}=.231, \mathrm{p}<0.009)$. On the other hand, no significant relationship was concluded between academic performance of students with test anxiety, test competence, academic competence and time management. In addition, students with good academic performance have better control of academic competence, test competence, time management and test anxiety. Conclusively, with raising the age and maturity, the health science students transform them to exhibit strategic studying in order to perform better in their academics. It could be suggested that efforts should be geared towards different types of assessment in learning and strategic studying that may have an impact on improved academic performance.

few studies, however, focus on factors that can be a measurement and non-measurement tool for students' performance. According to Sangsiry et al., five domains that may affect academic performance in developing strategies for student enhancement in academic, factors such as test anxiety, academic competence, test competence, time management and strategic studying methods on students' performance (Sansgiry et al., 2006). The academic performance refers to students' accomplishment at the different task by teachers and how well students deal in given task (Banquil et al., 2009). Academic competence is described as skills and capabilities which is significant for youth to be successful in school, academic competence in the broader spectrum is perceived in the sense of the ability of students' in managing and understanding the course load and materials that are

*Corresponding Author: badgujar@unikl.edu.my 
taught (Ma et al., 2009). Test competency can be explained as the ability of students in managing study load and handling a test or examinations. Test competency is operationally defined as student's ability to manage and cope with the amount of study material for examinations and/or tests (Kleijn et al., 1994). Test competence as student's ability to deal and muddle through the amount of course material for examinations. Further, it refers to difficulties associated with managing the study material as well as preparing for them for examination (Talib, 2012).

Time management is def ined as clusters of behavioral skill sets that are important in the organization of study or course load (Nankervis, 1998). Time management skills include activities performed by students such as planning in advance, prioritizing work, test preparation, and following schedules (Kirschenbaum \& Perri, 1982). Time management domain was operationalized as the ability of students to juggle leisure and study time to prepare for their examinations (Kleijn et al., 1994). Sansgiry et al. (2006) assert that test anxiety refers to activity that arouses students and is associated with students' experiences of assessment situation. Time management is the art of arranging, organizing, scheduling and budgeting one's time for the purpose of generating more eff icient work and productivity (Kaushar, 2013).

Test anxiety most often is known as a term for a severe anxiety condition. Test anxiety is a set of responses like worry, depression, nervousness, and task-irrelevant cognitions to a class of stimuli arising from an individual's experience of assessment or testing (Talib, 2012). Test anxiety is thought to have two components: i) a worry or cognitive component, and ii) an emotionality component. The worry component refers to student's negative thoughts that disrupt performance, while the emotionality component refers to effective and physiological arousal aspects of anxiety (Alam, 2013; Bonito, 2013).

Strategic studying is defined as the knowledge and application of effective study skills or techniques by students (Kleijn et al., 1994). Recognizing or distinguishing academic performance is a great task for an academician because it is a strong reaction factor of psychological and environmental outcome. In one of the studies conducted by West \& Sadoski (2011), they reported that strategic studying was significantly related to academic performance.

Numerous research is explored to anticipate the factors that affect the academic performance of students (Hijazi \& Naqvi, 2006). Subsequently, high level of academic performance may be researched into a broader perspective or spectrum of cognitive and non-cognitive strategies. Students' spectrum of study skills such as test and academic competency, strategic studying, test anxiety and time management and their influence on students' performance in academic were shown to be correlated (Sansgiry et al., 2004; 2006). As progression in academic takes place from year to year, students cognitive and non-cognitive domains such as time management, emotional intelligence and study strategies might transform from time to time. Thus, this may reflect students' maturity level to handle complex issues associated with academic performance and barriers that may lead them to study success. The excellence of a higher Institution of learning is measured by the quality assurance and standard performance of students through the measurement of exam results. Every student has a different background and potential that could be the reason behind the academic performance. All the knowledge that is provided is not imbibed completely by students. Lack of sufficient results or scarce information in determining factors of students' academic performance in health science stream, this is the main reason the researcher delved into this study. Consequently, this study is focusing on collective factors in anticipating the academic performance of health science students of a university. The primary objective of the present study was to determine the association of learning and study strategies on academic performance and students' academic years across the two years enrolment for health sciences program. Thus, this study distinguishes students' academic performance with regard to the five cognitive domains that may be the determinant factor in students' academic performance across two years.Varsity is one of the places where a methodical, establish, organized, aligned and explicitly oriented enlightenment of education is offered. It is through such an organized manner that the expertise and desired mindset or character of the learner is developing in tertiary education, but in a given class it is sometimes seen that there is a difference in achievement as a result of different factors that may affect the academic performance of students. At this stage, students are expected to direct their own learning to some extent, negatively affect their academic performance, especially if improper or inadequate assistance is not channeled. Consequently, this may have a psychological impact on the student's functional performance across years due to immaturity and incompetency in handling cognitive matters on academic performance. As a result of the immaturity of students enrolling in health science courses, vulnerability of dropout or withdrawal at certain years of enrollment may impact their performance cognitively. Therefore, the researcher is eager of determining the association between, time management, test competence, strategic studying, academic competence, test anxiety and the academic performance of varsity students across the two years of studying, hence, the need for this study on determinants of academic performance of a university student of health science program.

\section{Methodology:}

A cross-sectional design utilizing a survey instrument was administrated to 130 health science undergraduate students of year 1 and 2 studying in one of the University in 
RESEARCH ARTICLE

Perak, Malaysia during the academic year 2015-2016. A volunteer participation of students was involved in this study. Data collection prolonged for few days due to accessibility. The instrument utilized in the survey is mainly domains affecting academic performance and has been validated in the study of Sansgiry et al. 2006. The instrument was administered by a faculty member. The study instrument comprised of respondents' demographics and domains of test anxiety, academic competence, test competence, time management and strategic studying. Students reported their cumulative grade point average (GPA) as it was a primary indicator of academic performance.

Test Anxiety scale was adapted from a previously validated inventory that measured 10 items on a 5-point scale to rate the emotions (Sarason, 1980). Test competence, academic competence, strategic studying, time management were measured using previously reported valid scale (Kleijn et al., 1994; Lust \& Moore, 2006). Measurement of 5 -Likert scale ranging from $1=$ strongly agree $2=$ agree, $3=$ neutral, $4=$ disagree, $5=$ strongly agree. The Cronbach's coeff icient alpha values for Test Anxiety scale reported (o.72), Academic Competence (o.73), Test Competence (o.71), Time Management (o.73), and Strategic Studying (o.72) as an acceptable indicator to test the value of reliability (Sieber, 1980).

A total of 30 students were recruited in the pilot study. Subsequently, Mean, Standard deviation, and the correlation was used through the appropriate statistical package. Descriptive analysis, a t-test was used to analyze the data by using SPSS 12 and Microsoft Excel 2013. The Likert items responses were conducted using frequencies values and means. Mean scores for each item from questions were compared across two years of enrollment. Mean scores for each item was compared based on GPA.

Results and Discussion: Results are summerized below from Table-1 to 8 and figure $1 \& 2$.

Table 1: Descriptive Statistic: Mean; N= No. of students

\begin{tabular}{lcc}
\hline Variable & Year 1 $(\mathrm{N}=65)$ & Year 2 $(\mathrm{N}=65)$ \\
\hline Age & 18.25 & 19.15 \\
Gender: & & \\
Male & 15 & 40.1 \\
Female & 83 & 57.3 \\
Race: & & \\
Malay & 69.2 & 75.3 \\
Chinese & 7 & 5 \\
Indian & 13.2 & 9.2 \\
Others & 5.7 & 7 \\
GPA & $3.30(0.49)$ & $3.03(0.40)$ \\
\hline
\end{tabular}

Table 2. Reliability Test for Pilot Study

\begin{tabular}{lcl}
\hline Variable & Cronbach's Alpha & Total $(\mathrm{n})$ \\
\hline Test Anxiety & 0.72 & 30 \\
Academic Competence & 0.73 & 30
\end{tabular}

Test Competence Time Management Strategic Studying $\begin{array}{ll}0.71 & 30 \\ 0.73 & 30 \\ 0.72 & 30\end{array}$

Table 3. Determination of Test Anxiety, Academic Competence, Test competence, Time Management and Strategic Studying across the Two Years Enrolment. Mean +SD

\begin{tabular}{|c|c|c|c|}
\hline Variable & First Year, & Second Year & p values \\
\hline Test Anxiety & $3.37(0.5)$ & $3.56(0.4)$ & $\mathrm{p}>0.05$ \\
\hline Academic Competence & $3.68(0.2)$ & $3.73(0.2)$ & $\mathrm{p}>0.05$ \\
\hline Test Competence & $2.99(0.2)$ & $3.14(0.1)$ & $\mathrm{p}>0.05$ \\
\hline Time Management & $3.41(0.4)$ & $3.25(0.4)$ & $\mathrm{p}>0.05$ \\
\hline Strategic Studying & $2.92(0.2)$ & $3.57(0.2)$ & $\mathrm{p}<0.05$ \\
\hline
\end{tabular}

Table 4: Responses Determine Test Anxiety

\begin{tabular}{lllll}
\hline Variables & $\mathrm{D} \%$ & $\mathrm{~N} \%$ & $\mathrm{~A} \%$ & Mean (SD) \\
\hline $\begin{array}{l}\text {-Thoughts of doing poor } \\
\text { on exam }\end{array}$ & 8.0 & 18.6 & 73.4 & $3.91(0.9)$ \\
-Nervousness & 11.8 & 10.8 & 77.4 & $3.77(1.1)$ \\
-Perspiration & 8.0 & 19.3 & 72.7 & $3.79(0.9)$ \\
- Task-irrelevant cognitions & 36.7 & 17.3 & 46.0 & $3.13(1.2)$ \\
-Panicky & 22.6 & 22.7 & 54.7 & $3.39(1.1)$ \\
-Upset stomach & 50.0 & 18.7 & 31.3 & $2.64(1.2)$ \\
-Increased heartbeats & 20.6 & 26.7 & 52.7 & $3.38(1.1)$ \\
-Depression & 32.0 & 28.7 & 39.3 & $3.05(1.1)$ \\
-Worry & 15.3 & 18.7 & 66.0 & $3.74(1.2)$ \\
-Anxious even when & 9.3 & 20.7 & 70 & $3.84(1.2)$ \\
well-prepared & & & & \\
\hline
\end{tabular}

Test Anxiety = 3.46 $\pm 0.39($ Cronbach Alpha $=0.72)$

Table 5: Responses Determine Academic Competence

\begin{tabular}{lllll}
\hline Variables & $\mathrm{D} \%$ & $\mathrm{~N} \%$ & $\mathrm{~A} \%$ & Mean (SD) \\
\hline - Able to manage course load & $\mathbf{1 2 . 7}$ & $\mathbf{2 6 . 0}$ & 61.3 & $3.57(0.8)$ \\
- Comprehension & 18.0 & 21.3 & 60.7 & $3.48(0.9)$ \\
- Course taught is interesting & 11.3 & 16.7 & 72.0 & $3.79(0.9)$ \\
-Enjoyment & 10.0 & 22.0 & 68.0 & $3.96(0.9)$ \\
-Efforts & 8.0 & 14.0 & 78.0 & $3.96(0.9)$ \\
\hline
\end{tabular}

Academic competence $=3.75 \pm 0.22($ Cronbach Alpha $=0.73)$

Table 6: Responses Determine Test Competence

\begin{tabular}{lcccl}
\hline Variables & $\mathrm{D} \%$ & $\mathrm{~N} \%$ & $\mathrm{~A} \%$ & Mean (SD) \\
\hline - Easily manage study material & 42.0 & 16.7 & 41.3 & $3.03(1.0)$ \\
- Difficulty in preparing for test & 30.7 & 18.0 & 51.3 & $3.21(1.0)$ \\
- Coping with examination & 48.7 & 18.6 & 32.7 & $2.83(1.0)$ \\
$\quad \begin{array}{l}\text { tension } \\
\text { - Difficulty in managing study } \\
\text { material }\end{array}$ & 28.7 & 21.3 & 50.0 & $3.19(1.0)$ \\
\hline
\end{tabular}

Test competence $=3.07 \pm 1.0($ Cronbach Alpha $=0.73)$

Table 7: Responses Determine Time Management

\begin{tabular}{lllll}
\hline Variables & $\mathrm{D} \%$ & $\mathrm{~N} \%$ & $\mathrm{~A} \%$ & Mean (SD) \\
\hline $\begin{array}{l}\text { Diff iculty in combining study } \\
\text { and leisure time }\end{array}$ & 24.7 & 9.3 & 66.0 & $3.47(1.1)$
\end{tabular}


-Difficulty in studying regularly $\quad 22.7 \quad 10.7 \quad 66.6 \quad 3.54$ (1.1)

$\begin{array}{llllll}\text { - Cramming for examinations } & 17.3 & 11.3 & 71.4 & 3.59(1.1)\end{array}$

- Able to organize study and $\quad 46.0 \quad 8.0 \quad 46.0 \quad 2.99$ (1.1) leisure time easily

$\begin{array}{llllll}\text {-Test preparation in advance } \quad 51.3 & 10.0 & 38.7 & 2.87 & (1.1)\end{array}$

Time Management = 3.29 $\pm 0.33($ Cronbach alpha $=0.75)$

Table 7: Responses Determine Study Strategies

\begin{tabular}{lcccl}
\hline Variables & $\mathrm{D} \%$ & $\mathrm{~N} \%$ & $\mathrm{~A} \%$ & Mean (SD) \\
\hline -Advance planning & 46.0 & 2.7 & 51.3 & $3.02(1.3)$ \\
-Review course material & 40.7 & 6.6 & 52.7 & $3.11(1.2)$ \\
- Knowledge assessment before & 36.6 & 8.7 & 54.7 & $3.27(1.2)$ \\
$\quad$ exam & & & & \\
- Summarize the course material & 29.4 & 7.3 & 63.3 & $3.49(1.1)$ \\
-Judgment of test question & 31.3 & 10.0 & 58.7 & $3.33(1.2)$ \\
\hline
\end{tabular}

Study Strategies $=3.24 \pm 0.18($ Cronbach alpha $=0.72)$

Interpretation of scale for Table 4 to 8

D- Refer to Disagree; N- Refer to Neutral; A- Refer to Agree

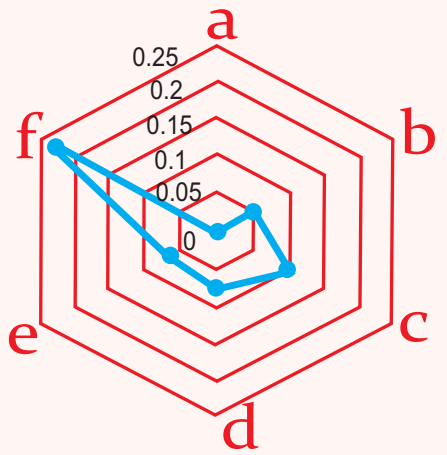

a: Variable

b: Test anxiety

c: Academic competence

d: Test comptetence

e: Time management

f: Strategic study

Table 7: Spearman Correlation Coefficients Analysis to Predict Student Performance (CGPA) \& Academic Performance Variables

Cronbach's alpha is a faster and reliable method to calculate the questionnaire's reliability. A pilot study of the questionnaire was undertaken to ensure the validity and reliability of the questionnaire (van Teijlingen et al., 2001). The report suggests the acceptable value score of 0.7 and higher indicates an acceptable reliability of the domains measured (Kerlinger \& Lee, 2000). It is envisaged that all items contribute to the reliability and construct validity of the questionnaire (Table-2).

Determination of Factors Affecting Students' Performance across the Two Years Enrolment: the total mean score of test anxiety, academic competence test competence, time management and strategic studying across the twoyears of enrollment is illustrated in Table-3. It was found that there is no significant correlation of test anxiety, academic competence, test competence and time management in academic performance between first year and second-year students. While strategic studying proved to affect positively on the academic performance of students when studying in higher level classes. In addition, the finding shows a significant correlation of strategic studying on academic performances $(\mathrm{r}=0.231, \mathrm{p}<0.009)$. Students with poor academic performance have the lowest test competence and higher test anxiety. This can be due to poor circumstances of students in managing academic course load and pitfalls in coping for exams and study materials (Sansgiry et al., 2006). In addition, a study of Rezazadeh \& Tavakoli (2009) revealed that there is no relationship between test anxiety and years of study.

Test Anxiety: the response of survey to determine test anxiety on students' performance is detailed in Table-3. The majority of students from the two groups reported nervousness and poor performance in examination along with severity in physical symptoms including perspiration, panicky and raised heartbeats affect their performance while taking the examination. Two out of three responses suffered through anxiety although their readiness was up to the mark. Consequently, first-year students' scored low in test anxiety (3.37 \pm 0.5$)$ compared to second-year students (3.56 \pm 0.4$)$. Indeed, there are no significant differences between student academic performance across two years and test anxiety $(\mathrm{r}=0.039, \mathrm{p}>0.633)$ as reflected in Table-9. This result supports the various studies of test anxiety that can have negative effects on academic performance (Alam, 2013; Chapell et al., 2005; Shapiro, 2014).

Academic Competence: the mean score for academic competence was $3.75 \pm 0.22$ reflected in Table-5. The response from this indicates that the provided course content was adequate and students were gratified. The majority of students were able to handle the course load with a better grasp of understanding. This reflects that students' view on the importance of managing their course material effectively to ensure improvement in their academic performance. The results of this study support the findings reported by Sansgiry et al. (2006).

Consequently, second-year students' scored higher in academic competence $(3.73 \pm 0.9)$ compared to first-year students (3.68 \pm 0.9$)$ reflected in Table-3. There were no significant differences between student academic performance across two years and academic competence $(\mathrm{r}=0.102, \mathrm{p}>0.215)$ as reflected in Table- 9 .

Test Competence: the results obtained for test competence on students' academic performance revealed the total mean test score of $3.06 \pm 0.17$ as per Table- 6 . Almost half of the students faced difficulties while preparing for the test, managing study materials and their comfort in preparing for the test. In general, test competence is an important factor in determining an academic performance. A notion states that students with difficulty in coping and managing the study materials have the tendency to have a lower grade. The results of test competence relate to the 
students' academic performance (Sansgiry et al., 2006; Sansgiry et al., 2004). Consequently, second-year students' scores higher in test competence (3.14 \pm 0.1$)$ compared to first-year students $(2.99 \pm 0.2)$ as in Table-3. There were no significant differences between student academic performance across two years and test competence $(r=0.77$, p>0.346) as reflected in Table-9.

Time Management: in Table- 7 , the mean score of response to determining time management on students' academic performance found to be $3.29 \pm 0.33$. The majority of students in both years agreed with the statement about their cramming in exams and difficulties while studying regularly. It may contribute to their stress during the exams. Consequently, first-year students' demonstrated better time management skills (3.41 \pm 0.4$)$ compared to secondyear students (3.25 \pm 0.4$)$ reflected in Table-3. There are no significant differences between student academic performance across two years and time management $(\mathrm{r}=0.63, \mathrm{p}>0.445)$ as reflected in Table-9. According to a study, Sansgiry et al. (2004) students achieve academic success with better time management skills. A review studies showed that time management training and planning helps students adjust their study time better and increase their academic performance (Zimmerman et al., 1994).

Study Strategies: this study on students' academic performance domain scored 3.24 \pm 0.18 is given in Table-8. Consequently, second-year students demonstrated better study strategies skills $(3.57 \pm 0.2)$ compared to first-year students (2.92 \pm 0.2$)$ reflected in Table-3. There were significant differences in the analysis between student academic performance across two years and study strategies $(\mathrm{r}=0.231, \mathrm{p}<0.009)$ as reflected in Table-9. Literature shows that strategic studying contributes to academic success (Lay \& Schouwenburg, 1993). According to a study by Norhidayah et al. (2009) there was a positive effect on academic performance when the students learning style and proper use of learning facilities are being combined together. However, our results are not consistent with these studies performed.

Conclusively, this study revealed the outcome of domains affecting students' performance in academics performance in various aspects. Our results outlined the need to evaluate factors such as test anxiety, academic competence, test competence, time management skills and strategic studying, which obstruct the success of the students. In addition, students with good academic performance have better control of academic competence, test competence, time management and test anxiety. Results of this present study underlined the significance of assessing factors of cognitive predictors in facilitating and magnifying academic performance of students. We also found that test anxiety, test competence, academic competence, time management would not affect the academic performance of students across two years except for strategic studying.

\section{Acknowledgements:}

Authors would like express their sincere gratitude to the Students of Health sciences, University Kuala Lumpur, Royal College of Medicine Perak, for theirvoluntarily participation in this study.

\section{References:}

Alam, M.M. (2013): A study of test anxiety, self-esteem, and academic performance among adolescents. . IUP J. Organ. Behav., 12(4):33-43.

Allen, J.D. (2005): Grades as Valid Measures of Academic Achievement of Classroom Learning. The Clearing House: J. Educ. Strat., Issues Ideas, 78(5):218-223.

Banquil, K.C.N., Leano G.A., Rivero, M.A., Burce, C.A., Dianalan, S.N., Matienzo, A.R., Timog, N.U. (2009): Social networking sites affect one's academic performance adversely. Retrieved May 2, 2017, from http://www.ust.edu.ph

Bonito, S.R. (2013): Motivation factors in Distance Education. Int. J. Educ. Pedagog. Sci., 7(2): 458-46o.

Chapell, M.S., Blanding, Z.B., Silverstein, M.E., Takahashi, M., Newman, B., Gubi, A. \& McCann, N. (2005): Test Anxiety and Academic Performance in Undergraduate and Graduate Students. L. Educ. Psychol., 97(2):268-274.

Hijazi, S.T. \& Naqvi, S.M.M.R. (2006): Factors Affecting Students' Performance: A Case of Private College. Bangl. e-J. Soc., 3(1): 90-99.

Kaushar, M. (2013): Study of Impact of Time Management on Academic Performance of College Students. IOSR J. Bus. Manag., 9(6): 59-6o.

Kerlinger, F.N. \& Lee., H.B. (200o): Foundations of behavioral research. Pub. by: Wadsworth Thomson Learning, South Melbourne.

Kirschenbaum, D.S. \& Perri, M.G. (1982): Improving academic competence in adults: A review of recent research.J. Counsel. Psychol., 29(1): 76-94.

Kleijn, W.C., van der Ploeg, H.M. \& Topman, R.M. (1994): Cognition, Study Habits, Test Anxiety, and Academic Performance. Psycholo. Rep., 75(3):1219-1226.

Lay, C. \& Schouwenburg, H. (1993): Trait Procrastination, Time Management, and Academic Behavior. L. Soc. Behav. Personal., 8(4):647-662. .

Lust, E. \& Moore, F.C. (2006): Emotional Intelligence Instruction in a Pharmacy Communications Course. Am. I. Pharm. Educ., 70(1): 06.

Ma, L., Phelps, E., Lerner, J.V. \& Lerner, R.M. (2009): Academic Competence for Adolescents Who Bully and Who Are Bullied. J. Early Adolescence, 29(6): 862-897.

Talib, N.S.S.S. (2012): Determinants of Academic Performance of University Students. Pak. J. Psycholog. Res., 27(2):265-278.

Nankervis, A.R. (1998): Book Reviews: James W. Walker (1992): Human resource strategy New York: McGraw Hill, pp. 378 Asia Pac. J.Hum Resou., 35(3):115-117.

Norhidayah, A., Kamaruzaman, J., Ali, S., Mokhtar, N., Syafena, A. \& Andin, S. (2009): The Factors Influencing Students' Performance at Universiti Teknologi MARA Kedah, Malaysia. 
Can. Res. Deve. Cen. Sci. Cul., 3(4):81-90.

Rezazadeh, M. \& Tavakoli, M. (2009): Investigating the Relationship among Test Anxiety, Gender, Academic Achievement and Years of Study: A Case of Iranian EFL University Students. Engl.Lang. Teach., 2(4):68-74.

Sansgiry, S.S., Bhosle, M. \& Sail, K. (2006): Factors That Affect Academic Performance Among Pharmacy Students. Am.. Pharm.Educ., 70(5):104.

Sansgiry, S.S., Kawatkar, A.A., Dutta, A.P. \& Bhosle, M.J. (2004): Predictors of Academic Performance at Two Universities: The Effects of Academic Progression. Am. J. Pharm. Edu., 68(4): 103.

Sarason, I.G. (1980): Test anxiety: Theory, research, and applications. Pub. by: Lawrence Erlbaum Associates, Incorporation.

Shapiro, A.L. (2014): Test anxiety among nursing students: A systematic review. Teach. Learn. Nurs., 9(4):193-202.
Sieber, J.E. (1980): Defining test anxiety: problems and approaches. In: Sarason IG, ed.. Test Anxiety: Theory, Research and Applications. Pub. by: Lawrence Erlbaum and Associates; pp. 1540.

van Teijlingen, E.R., Rennie, A.M., Hundley, V. \& Graham, W. (2001): The importance of conducting and reporting pilot studies: the example of the Scottish Births Survey. J. Adv. Nurs., 34(3): 289-295.

West, C. \& Sadoski, M. (2011): Do study strategies predict academic performance in medical school? Med. Educ., 45(7): 696-703.

Zimmerman, B.J., Greenberg, D., \& Weinstein, C.E. (1994). Selfregulating academic study time: A strategy approach. In D. H. Schunk \& B. J. Zimmerman (Eds.), Self-regulation of learning and performance: Issues and educational applications (pp. 181-199). Pub. by: Lawrence Erlbaum Associates .

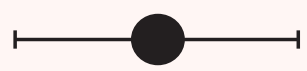

